\title{
Perception of printing workers regarding occupational health hazards and safety measures
}

\author{
Mona Mohamed Abd El-Maksoud*1, Nadia Abdel-Latif Ali ${ }^{2}$ \\ ${ }^{1}$ Community Health Nursing, Faculty of Nursing, Helwan University, Cairo, Egypt \\ ${ }^{2}$ Community Health Nursing, Faculty of Nursing, Cairo University, Cairo, Egypt
}

Received: March 25, 2020

DOI: $10.5430 /$ jnep.v10n8p39
Accepted: May 5, 2020

Online Published: May 17, 2020

\begin{abstract}
Background and objective: Printing workers are frequently exposed to many forms of occupational hazards while doing their jobs. Little research was done in Egypt about printings occupational hazards, which constitute a huge burden on the affected workers and employment settings. Therefore, the present study aimed to investigate the perception of occupational hazards and safety measures among printing workers.

Methods: Descriptive analytic design was carried out the current study at the Egyptian Book House Press in Cairo on a purposive sample of 200 workers using a structured questionnaire to collect data, which include demographic data, occupational hazards, predisposing factors and safety measures as perceived by workers.

Results: The results revealed that the majority of workers exposed to moderate level of occupational health hazards and safety measures. The most hazards the printing workers are exposed to it, are health, chemical, injury and psychological hazards. Also, there is a highly statistically significant negative correlation with total occupational hazards and safety measures.

Conclusions: The study can be concluded that the workers exposed to moderate occupational hazards. As well, the majority of workers stated that there is a moderate level of safety measures to occupational hazards in their workplace. Therefore, this study recommended that continuous training of the printing workers on safety guidelines and enforcement of standard safety practices to decrease the potential occupational hazards.
\end{abstract}

Key Words: Printer workers, Occupational hazards, Safety measures, Predisposing factors

\section{INTRODUCTION}

Many people spend a significant portion of the day and night at work in order to meet their economic and social needs. Significant growth in scientific and technological development can lead to increase in different health hazards. During work, people are often faced with various safety hazards and risks, which can expose them to numerous adverse health problems. Occupational hazards can be associated with a variety of factors, including physical, chemical, and biological agents as well as undesirable working conditions among others. Health hazards in the workplace form a major threat to a large proportion of the world's population. Approximately $75 \%$ of the world labor forces are living in developing countries, but only between $5 \%-10 \%$ have access to occupational health services. ${ }^{[1]}$ The proportion of occupational accidents and diseases are increasing in developing countries. Recently, International Labor Organization estimated that globally, more than 120 million accidents occur in the workplace; about 2.2 million people die every year, and too much economic cost of injuries and illness resulted from work accidents. ${ }^{[2]}$ Egypt.

*Correspondence: Mona Mohamed Abd El-Maksoud; Email: Drmona158@gmail.com; Address: Faculty of Nursing, Helwan University, Cairo, 
In recent years, the numbers of the printing and publishing sectors in Egypt and the overall world have increased extremely; it has a lot number of workers in it. So their work environment is a very important determinant of health; it can influence health positively or negatively, and for most people, work is essential for economic, social as well as physical wellbeing. ${ }^{[3]}$ Therefore, the presence of hazards in the workplace due to factors such as dust, toxic chemicals, heat stress, noise, and dangerous machines causes the massive burden of work-related injuries, diseases and sometimes death. ${ }^{[4]}$ As well, Prica, et al. (2016) ${ }^{[5]}$ added that there many occupational exposures have been observed for among printing workers as exposures to organic solvents, mineral oils, pigments, resins, paper dust, adhesives, polycyclic aromatic hydrocarbons, acrylates, lead, and noise, carry heavy boxes of paper, chemicals or printed materials.

The impact of occupational hazards on printing workers in developing countries is higher than those in industrialized countries. This may be due to lack of safety training, job stress, the absence of safety signs, sleep problems, workload. A safe working environment and practices are important to avoid the occurrence of accidents and ensure optimum work performance. ${ }^{[6]}$ Besides, Othman, et al. (2017) ${ }^{[7]}$ stated that the workers play an important role in protecting themselves from exposure to occupational health hazards, though following the regulation of safety procedure in the work environment as proper lifting methods, and determine the needed precaution and control measurements allow workers with adequate training and physical capabilities to attempt their work tasks safely. Hence, if it is difficult to avoid workers' health problems and overcome the occupational health hazards in printing places, occupational injuries and loss of productivity will continue and considered a major challenge in the printing industry in the future. ${ }^{[2]}$ Indeed, the occupational health nurses play a vital role in workplace settings through providing education about preventative measures to improve the health and safety of workers in a different work setting as those settings most likely to the presence of injuries, toxins, machinery, or heavy equipment. Occupational health nurses strive to ensure that all health and safety standards are met to safeguard the health and well-being of employees as well they work toward maximizing employee productivity also act as advocates for the rights of employees by ensuring their access to preventative health and safety measures. ${ }^{[8]}$

On the other hand, there are not enough studies in Egypt and/or the overall world that are cited on worker health and occupational safety in the printing and publishing sector for health hazards analyses. Alongside these facts are mentioned above, it is interesting and useful to examine the perception of printing workers about occupational health hazards and workplace safety measures to provide safe work environments, and healthy workers, consequence it is leading to sustainable development.

\subsection{Aim of the study}

This study aimed to investigate the perception of workers regarding occupational health hazards and safety measures in the printing sector.

\subsection{Research questions}

- What are occupational health hazards among printing workers?

- What is the safety measures followed at the printing sector?

\section{SUBJECTS AND METHODS}

\subsection{Research design}

Descriptive analytic study design was used to achieve the aim of this study.

\subsection{Sampling and setting}

The current study enrolled purposive sample of all the printing workers (200) are working at the Egyptian Book House Press in Cairo. The workers were chosen according to the following inclusion criteria:

- Starting work from at least 6 months

- Working in printing process

- Available during time of data collection

\subsection{Tools of data collection}

Based on the literature review and pervious studied, the researchers developed data collection instruments, It was written in Arabic language, the interviewing questionnaire included the following parts:

Part 1: Demographic data and medical history: such as age, sex, years of work, education, medical diseases, and training courses on occupational hazards and safety measures and type of occupational accidents at workplace.

Part II: A structured questionnaire about assessing the perception of workers regarding occupational hazard as chemical, biological, injuries, health and psychological and social hazards, and predisposing factors related to an occupational hazard.

Part III: Safety measures questionnaire, it includes questions about safety measures are following in the Book House Press according to the perception of workers as dealing carefully with sharp tools, committing with safety instructions, etc.

\section{Scoring:}

- Five-point Likert scale, were used to assess occupational 
hazards, it ranged from (1) never, (2) rarely, (3) sometimes, (4) usually, and (5) always.

- The predisposing factors questionnaire was assessed through using five-points Likert scale that ranged from (1) which strongly disagree, (2) disagree (3) unsure, and (4) agree, and (5) strongly agree.

- Safety measures were assessed by using three points Likert scale as follows: disagree (1), uncertain (2), and (3) agree.

\subsection{Validity and reliability of the tool}

For testing the validity of the tools, three experts in community health nursing assess the comprehensive content, and clarity of the items. Modifications made based on their recommendation. The content and face validity of the study tools were measured to evaluate the individual items as well as the entire tools used for the study as being relevant and appropriate to test what they wanted to measure.

The reliability of the tools was checked by Cronbach's alpha test. Test of reliability for the occupational health hazards and safety measures questionnaire Cronbach's coefficient alpha showed 0.92 during the pilot study. This indicated that the questionnaire is highly reliable.

\subsection{Pilot study}

A pilot study was applied to a sample of $10 \%$ of workers, to test the clarity of the tools and time needed to fill it. Based on the finding of the pilot study, the necessary modifications were done, namely rephrasing, utilizing simpler semantic for the statements, those workers were excluded from the sample.

\subsection{Ethical consideration}

Official permission was gained through the appropriate channels, from Faculty of Nursing/Helwan University and director of the Egyptian Book House Press before the beginning of the study. As well, written informed consent obtained from the workers before the questionnaire was administered. Confidentiality and anonymity were ensured, whereby participants were not allowed to reveal names on the questionnaire. Subjects were assured that this data will not be reused in another research without their permission, and the data collected will be used only for the research.

\subsection{Data collection procedure}

Full disclosure of the nature of the study and purpose of the study was explained briefly to all participants who fulfill the criteria prior to their participation in the present study by the researchers. Furthermore, they were assured that they could withdraw from the study at any time. After that, the questionnaire was distributed to the workers during their working time with complete explanation of how to answer the questionnaires, and those who can't read and write were interviewed individually.

The time spent with each worker ranged from 20-30 minutes. Data were accomplished in around two months, starting from the beginning of July to August 2019.

\subsection{Statistical design}

The obtained data were reviewed and prepared for computer processing, coded, analyzed and tabulated, using statistical package for the social sciences "SPSS" software version 21. Data were presented using descriptive statistics in the form of frequencies and percentages, means, standard deviations. Pearson's correlation coefficient (r) was used for assessment of the interrelationships among quantitative variables. The threshold of significances is fixed at 5 percent ( $p$-value). The $p$-value $>.05$ indicates non-significant result. $p$-value $\leq .05$ is significant. The $p$-value $\leq .01$ indicates highly statistically significant.

\section{Results}

Tables 1 reveal that, almost less than two thirds of the studied sample $(60.5 \%)$ was aged between 25 to 45 years old, while $8 \%$ were above 50 years old with a mean age of $41.79 \pm$ 10.164 , majority of them male and married $(71 \%, 79.5 \%$, respectively). Concerning the educational level, $79.5 \%$ of the studied sample had below university education. Regarding the type of work, the average of the studied sample regarding their years of work was $16.86 \pm 10.144$, majority (91.4\%) of their monthly income was enough.

Table 2 indicates that, slightly more than half $(51.5 \%)$ of the studied sample was suffering from chronic disease as hypertension $(90.5 \%)$, while $11 \%$ have rheumatic disorders. Less than three thirds $(72.5 \%)$ of the studied sample indicated that they received information related to occupational hazards and work safety from different sources, $60 \%$ of them took training courses. Also Table 2 illustrates that, $19.5 \%$ of the studied sample have been exposed to occupational accidents at workplace.

Figures 1, 2 and 3 show that, 79\% of the studied sample have moderate occupational hazards, while the rest of them (21\%) expose to high occupational hazards, and $75 \%$ of them reported that there a moderate level of predisposing factors to occupational hazards, while, $87 \%$ have a moderate use of safety measures against occupational hazards.

Concerning occupational hazards, the results of this study are not mentioned here, found that the printing workers were exposed to different occupational hazards, regards to health hazards, the findings revealed that about half of them (48\%) sometimes had backaches and arm pain also sometimes have 
body pain, leg pain and sleep disturbance. Sore throat, allergy dizziness and more than two-thirds $(69 \%)$ of them had a headache, while one third (33\%) had visual, respiratory disturbance, and skin disorders.

Table 1. Frequency distribution of the studied sample according to their demographic data $(n=200)$

\begin{tabular}{|c|c|c|}
\hline Variables & $\mathbf{n}$ & $\%$ \\
\hline \multicolumn{3}{|l|}{ Age } \\
\hline $25-35$ years & 71 & 35.5 \\
\hline $36-45$ & 50 & 25 \\
\hline $46-55$ & 63 & 31.5 \\
\hline$\geq 56$ & 16 & 8 \\
\hline \multicolumn{3}{|l|}{$\mathrm{M} \pm \mathrm{SD} 41.79 \pm 10.164$} \\
\hline \multicolumn{3}{|l|}{ Gender } \\
\hline Male & 142 & 71.0 \\
\hline Female & 58 & 29.0 \\
\hline \multicolumn{3}{|l|}{ Marital status } \\
\hline Single & 32 & 16.0 \\
\hline Married & 159 & 79.5 \\
\hline Divorced/widow & 9 & 4.5 \\
\hline \multicolumn{3}{|l|}{ Educational level } \\
\hline Illiterate/or Read and write & 27 & 13.5 \\
\hline Primary school & 52 & 26.0 \\
\hline Preparatory school & 13 & 6.5 \\
\hline Secondary school & 67 & 33.5 \\
\hline Higher education & 41 & 20.5 \\
\hline \multicolumn{3}{|l|}{ Years of work } \\
\hline \multicolumn{3}{|l|}{$\mathrm{M} \pm \mathrm{SD} 16.86 \pm 10.144$} \\
\hline \multicolumn{3}{|l|}{ Monthly income } \\
\hline Enough and more & 5 & 2.5 \\
\hline Enough & 180 & 91.4 \\
\hline Not enough & 12 & 6.1 \\
\hline
\end{tabular}

Regarding injuries hazards, results indicates that $49 \%$ of workers reported that they often slipped or fall on wet floors especially during emergencies, after fires, or chemical injuries, or when carrying stuff, $45.5 \%$ said that usually that they face stabbings or injuries from sharp tools, especially when lifting tools or cutting extremities by razors or sharp edges. On the other hand, $60 \%$ reported that they sometimes suffer from body injuries due to falling of heavy equipment or machines.

The results of this study found chemical hazards, which shows that, $38.5 \%$ and $41.5 \%$ of the studied sample reported that, usually they have eye allergy, nose and throat from dust or washing liquids and acute poisoning due to printing material. Also, $36 \%$ and $36.5 \%$ reported that, they have chronic intoxication from lead, nickel, and mineral salts and have been exposed to volatile hydrocarbons. As well, Results illustrate that the slightly more than half of the studied sample $(59.5 \%)$ reported that sometimes they have increased temper. As for the other psychological symptoms the studied sample rarely has these symptoms. Also indicates that, almost the majority of the studied sample was not exposed to biological hazard, and rarely having sociological hazards.

Table 2. Frequency distribution of the studied sample according to their medical data $(n=200)$

\begin{tabular}{lcc}
\hline Variables & $\mathbf{n}$ & $\mathbf{\%}$ \\
\hline Do you have any chronic diseases? & & \\
Yes & 103 & 51.5 \\
No & 97 & 48.5 \\
Type of disease? & 181 & 90.5 \\
High blood pressure & 14 & 7.0 \\
Cardiac diseases & 3 & 1.5 \\
Osteoporosis & 22 & 11.0 \\
Rheumatic disorders & 145 & 72.5 \\
Did you receive any information about the occupational \\
environment hazards and work safety? & \\
Yes & 55 & 27.5 \\
No & 121 & \\
What are the sources of this information? & 60.5 \\
Training courses & 22 & 11.0 \\
Internet/books & 30 & 15.0 \\
TV/radio health programs & 50 & 25.0 \\
Friends &
\end{tabular}

Have you been exposed to any occupational accidents?

$\begin{array}{lll}\text { Yes } & 39 & 19.5 \\ \text { No } & 167 & 83.5 \\ \text { Type of hazard } & & \\ \text { Broken Leg } & 5 & 15.1 \\ \text { Toe amputation } & 5 & 15.1 \\ \text { Hand lacerations } & 14 & 42.4 \\ \text { Slipping from the stairs } & 9 & 24.2 \\ \text { Trauma } & 6 & 18.2\end{array}$

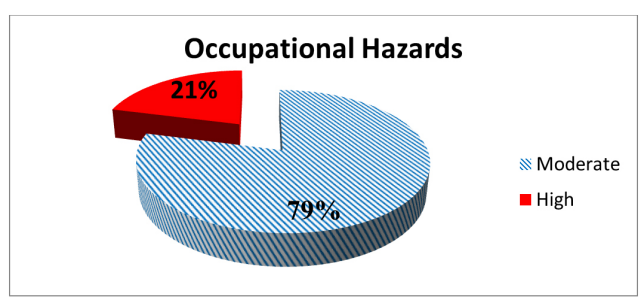

Figure 1. Distribution of the studied sample according to levels of occupational hazards

Table 3 shows that mean total occupational hazards were $213.13 \pm 26.54$, and the high hazard workers' exposure was health hazards (78.20 \pm 9.27$)$, and chemical (38.65 \pm 5.20$)$, injuries and psychological (32.18 $\pm 3.50,29.29 \pm 7.91)$, 
and fewer hazards were biological and sociological hazards $(15.66 \pm 4.01,24.97 \pm 3.62$, respectively). Also, the table clarifies that the total mean of predisposing factors (18.75 \pm $7.32)$ and safety measures $(21.57 \pm 4.42)$.

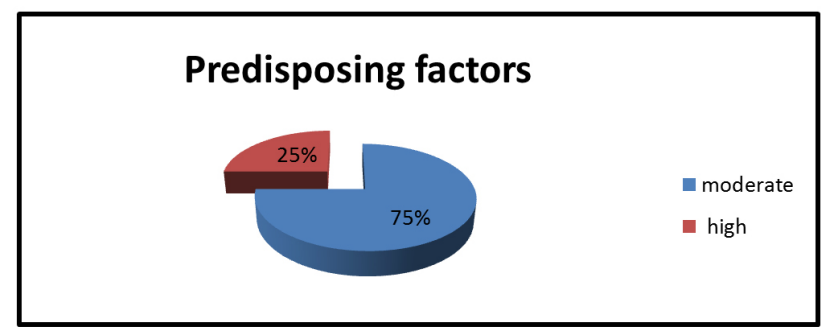

Figure 2. Distribution of the studied sample according to levels of predisposing factors to occupational hazards

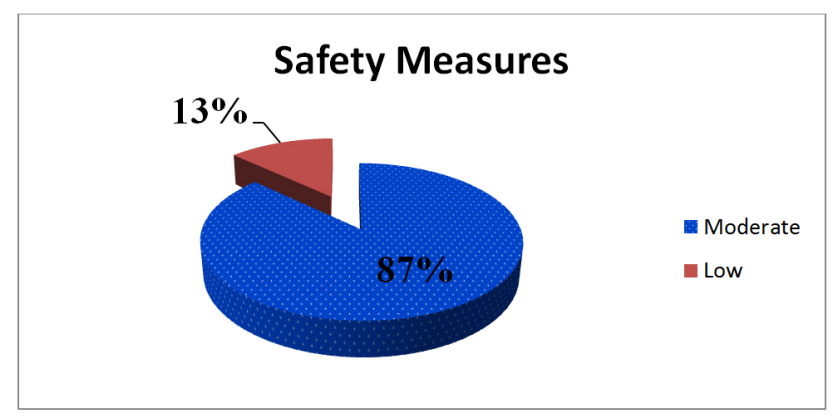

Figure 3. Distribution of the studied sample according to safety measures at workplace

Table 3. Mean and standard deviation of the occupational hazards, predisposing factors and safety measures $(\mathrm{n}=200)$

\begin{tabular}{lll}
\hline Totally & Mean & SD \\
\hline Injuries hazards & 32.18 & 3.50 \\
Health hazards & 78.20 & 9.27 \\
Chemical hazards & 38.65 & 5.20 \\
Biological hazards & 19.15 & 7.89 \\
Psychological Hazards & 29.29 & 7.91 \\
Sociological hazards & 15.66 & 4.01 \\
Total Occupational hazards & 213.13 & 26.54 \\
Total predisposing factors & 18.75 & 7.32 \\
Total safety measures & 21.57 & 4.42 \\
\hline
\end{tabular}

Table 4 shows that, there were highly statistically significant correlation between total subscale of injuries, chemical hazards and total predisposing factors $(r=.333, .444, p=.000)$, and highly statistically significant correlation between total safety measures and total subscale of injuries, health, and psychological hazards $(r=-.217,-.257,-.222, p=.000)$. Also, there were highly statistically significant positive correlation between total occupational hazards and total predisposing factors as $(r=.484, p=.000)$ and highly statistically significant negative correlation with the total safety measures as $(r$ $=-.992, p=.000)$.

Published by Sciedu Press
Table 4. Correlation matrix among the occupational hazards, predisposing factors and safety measures against occupational hazards total subscales and total scales $(\mathrm{n}=$ 200)

\begin{tabular}{llll}
\hline Occupational hazards & $\begin{array}{l}\text { Predisposing } \\
\text { factors }\end{array}$ & $\begin{array}{l}\text { Safety } \\
\text { measures }\end{array}$ \\
\hline Injuries hazards & $r$ & $.333^{* * *}$ & $-.217^{* *}$ \\
Health hazards & $p$ & .000 & .002 \\
& $r$ & .126 & $-.257^{* *}$ \\
Chemical hazards & $p$ & .081 & .000 \\
& $r$ & $.444^{* *}$ & -.113 \\
Biological hazards & $p$ & .000 & .116 \\
Psychological & $p$ & .090 & -.111 \\
Hazards & $r$ & .111 & .122 \\
Sociological hazards & $p$ & .123 & $-.222^{* *}$ \\
Total occupational & $p$ & $.176^{*}$ & .002 \\
hazards & $r$ & .014 & -.082 \\
**Correlation is significant at the 0.01 level (2-tailed), *Correlation is \\
significant at the 0.05 level (2-tailed).
\end{tabular}

Table 5 reveals that, age showed statistically significant relationships with injuries hazards subscale and total predisposing factors scale as $(r=.178, p=.012$, and $r=.356, p$ $=.000$, respectively). Also, years of work was statistically significant relationship with chemical hazards, and predisposing factors as $(r=.180, p=.011$, and $r=.351, p=.000)$ respectively.

Table 5. Relationship between age and years of work to the occupational hazards, predisposing factors and safety measures $(\mathrm{n}=200)$

\begin{tabular}{|c|c|c|c|}
\hline Variables & & Age & Years of work \\
\hline \multirow{2}{*}{ Injuries hazards } & $r$ & $.178^{*}$ & .130 \\
\hline & $p$ & .012 & .067 \\
\hline \multirow{2}{*}{ Health hazards } & $r$ & .047 & -.002 \\
\hline & $p$ & .508 & .979 \\
\hline \multirow{2}{*}{ Chemical hazards } & $r$ & .101 & $.180^{*}$ \\
\hline & $p$ & .158 & .011 \\
\hline \multirow{2}{*}{ Biological hazards } & $r$ & .001 & .091 \\
\hline & $p$ & .988 & .201 \\
\hline \multirow{2}{*}{ Psychological Hazards } & $r$ & -.101 & .049 \\
\hline & $p$ & .158 & .495 \\
\hline \multirow{2}{*}{ Sociological hazards } & $r$ & -.122 & .019 \\
\hline & $p$ & .087 & .793 \\
\hline \multirow{2}{*}{ Total occupational hazards } & $r$ & .126 & .049 \\
\hline & $p$ & .077 & .490 \\
\hline \multirow{2}{*}{ Total predisposing factors } & $r$ & .356 & .351 \\
\hline & $p$ & $.000^{* *}$ & $.000^{* *}$ \\
\hline \multirow{2}{*}{ Total safety Measures } & $r$ & .130 & .062 \\
\hline & $p$ & .070 & .392 \\
\hline
\end{tabular}

**Correlation is significant at the 0.01 level (2-tailed) 


\section{Discussion}

Workers in printing books face many hazards in their work environment, and these hazards have the potential to cause injuries or illness. Exposure to workplace hazards is related to the availability of basic features such as ventilation, lighting, dust, noise, and fire facilities. The study assessed the perception of occupational hazards and the use of safety measures among printing workers.

Regarding the description data on occupational health hazards and safety measures among printing workers, the findings from this study highlight that more than half of printing workers are within age $25-45$, which this age is highly productive. Also, the males were more constituted of this work, nearly to two-thirds of them working as printing workers and technician that work, this might be this work need more power and efforts the females can't tolerate it. As well, a major proportion of the workers had primary, preparatory and secondary education which might be due to these processes are not highly technical. A worthy proportion of workers have been working in the printing sector for a long duration, this might be they had adequate experiences on printing sectors. The results of study done in Turkey by Yilmaz, et al $(2015)^{[9]}$ confirm our finding that the majority of workers were male within the age group from 18-45 and had primary to secondary school, and most of the workers worked in the printing beside the school, which they had adequate experiences on printing. This confirms that the workers must have adequate knowledge, training and experiences in that job.

According to research results, more than half of the workers had chronic diseases, especially hypertension, this might be due to that about forty percent of them their age were more than 45 years old, and most chronic disease is common among this time of age. As well the study mention that the sixty percent of workers had training bout the occupational environment hazards and work safety, this might be the majority of workers worked high portion of duration in this work as mentioned above that give them a chance to take a training course and had much experience in safety measures. Workers' training about occupational hazards and safety is very important to perform the work efficiently and make the work environment safe for the workers. This result consisted with finding of a study done in Taiwan among workers in the printing industry by Tsai et al. (2016) ${ }^{[10]}$ who reported that $59.9 \%$ of employers taken work place safety and health training. As well, a study was done in Candia by Denton, et al. (2018) ${ }^{[11]}$ who assess the perception of workers about safety at work, which reported that the studied group mentioned that they had appropriate and adequate training about the safety of the work environment. This was in line with Kelloway $(2017)^{[12]}$ who stated that effective training in workplace safety was very effective in preventing or decrease the work accident. Inconsistence, a study done in Ethiopia by Gebremeskel and Yimer (2019) ${ }^{[2]}$ they reported that $16.8 \%$ of workers were received health and safety training. According to the results, this study reported that more than nineteen percent exposed to occupational accidents at workplace as broken legs, toe amputation, and hand laceration and others. On the same line Yilmaz et al. (2015) ${ }^{[9]}$ found that $22 \%$ of printings workers exposed to minor accidents during the workday as laceration, incision, and trauma, while $6 \%$ of them exposed to major accidents leading to amputation and broken.

Occupational hazards are leading to several health problems among workers due to a lack of safety at the workplace. The study findings found that according to workers' perception more than three-quarters of the studied sample exposed to moderate level of occupational hazards, while more than twenty percent of workers exposed to high occupational hazards. This means that the workplace is moderate safe and the workers did not completely followed the safety measures at work. This result was same when it's compared with previous studies done in Malaysia to evaluate existing and potential hazards for printing workers by Othman et al. (2017) ${ }^{[7]}$ who found that the medium level of hazard for the printing workers was $72.3 \%$ of the total hazards while the rest of them for the high level of hazards, which the workers were in the range of moderate to high exposure to occupational hazards.

According to the workers' perceptions, this finding pointed to that the most hazards; the printing workers can expose to it were health, chemical, injury and psychological hazards. Regarding health hazards, the results of this study revealed that about half of them usually had backaches and arm pain also sometimes have body pain, leg pain and sleep disturbance. Sore throat, allergy dizziness and more than two-thirds had a headache, while one third had visual, respiratory disturbance, and skin disorders. These results agree with Othman et al. $(2017)^{[7]}$ who reported that the workers are exposed to the high risk of hazards; these hazards may cause ergonomics to the workers. As well, Martin (2019) ${ }^{[13]}$ added the continual exposure to the ultraviolet light of machines can cause eyestrain and headache.

Concerning the chemical hazards, more than thirty percent usually had eye allergy, nose and throat from dust and washing liquid, skin allergy, irritation and respiratory allergy from exposure to isooynates and printing inks and less than half had acute poisoning from printing materials. On the same line, Othman et al. (2017) ${ }^{[7]}$ stated that the workers exposed to chemical hazards as lung irritation and respiratory system discomfort from inhalation of organic vapors. Furthermore, the handling of raw materials can lead to skin irritation and 
contamination, as well, a previous study done in Japan by Kitamura et al. (2014) ${ }^{[14]}$ who find a high prevalence of breathlessness and reduce of lung function, and allergic asthma among photocopiers workers, as well as some of them had allergic dermatitis. Therefore, it is important to provide the workers with information and guidelines for using chemical substances during printing to ensure the safe use of chemicals in the workplace.

As regards injury hazards, the results found that sixty percent of workers reported from their perception that the workers that they sometimes suffer from body injuries due to falling of heavy equipment and also about fifty percent usually face injuries from sharp tools, Othman et al. (2017) ${ }^{[7]}$ reported that the workers are exposed to a higher risk of injuries from heavy labor of carrying and moving the raw materials, also this may cause ergonomics to the workers. Regarding Psychological hazards, the finding of a study reported that almost two-thirds of workers had increased temper or stress results from working on a printing machine, on the same line, Martin (2019) ${ }^{[13]}$ stated that copier machines produce noise and heat, which can cause stress and fatigue.

According perception of printing workers towards predisposing factors for occupational hazard, the results stated that three quarter of printing workers mentioned that moderate level of predisposing factors to occupational hazards and rest of them mentioned there was high level of these factors, most of these factors were mentioned as lack of safety equipment, lack of heave machines lifting equipment, lack periodical checkup of workers and vaccine them, also lack information to use the new equipment. This result was consistent with Denton et al. (2018) ${ }^{[11]}$ stated it is needed special equipment at the workplace as mechanical lifting devices and transfer care to assist the workers and decrease the physical demands on workers and fewer work accidents, as well, the author added when adequate information is provided to workers potential risks are assessed, and the organization allows the workers to take training about safety measurements, the perception of workers about workplace safety will be increased.

Regarding the perception of workers regards the safety measures against occupational hazards, the findings of this study found that the majority of workers stated that there moderate level of safety measure to occupational hazards in the workplace, so it is important of commitment the rules of safety measures at the workplace, wearing anti-radiation garments to limit exposes to radiation and chemical substances. There is a similar situation in many countries in printing and publishing sector, a study done in Kenya to assess psychosocial and mechanical-hazards to printing workers by Starovoytova

Published by Sciedu Press
$(2017)^{[15]}$ who found that $80 \%$ of the employees reported that the work equipment and machinery should be regularly checked, to protect workers from health hazards. This was in an agreement with Goebel (2015) ${ }^{[16]}$ who conducted that follows the rules and guidelines for safety using the photocopier machines, the health risks can be avoided. As well, Denton et al. (2018) ${ }^{[11]}$ mentioned that the workers should comply with or work within the regulation of safety measures of the workplace. Besides that, Prica et al. (2016) ${ }^{[5]}$ stated that the work printing environment affects the health of the workers, so to reduce these hazards it is important to change attitudes and practices of workers towards preventing and reducing occupational hazards. Also, follow the preventive regulations and safety procedures as wearing protective equipment, good air ventilation indoors. A study among printing industry workers in USA by Casey and Hawley $(2016)^{[17]}$ found that wearing protective clothes and room ventilation were associated with a lower prevalence of eye irritation, rhinitis, and allergic skin reactions.

Concerning the correlation occupational health hazards and safety measures, the results of this study found that a negative statistically significant correlation between total occupational hazards and total safety measures, this means when the protective measures are used in the workplace and the workers had training and follow the guidelines and rules for safety measures those will lead to the decline of occupational hazards that affect on workers' health. In similarity to the previous study done in Cairo by Ibrahim et al. (2018) ${ }^{[18]}$ who stated adequate preventive and control measures in the work environment are leading decrease work hazards also authors found wearing protective clothes, good ventilation and lighting in the printing shop were statistically significantly associated with a lower prevalence of occupational hazards. According to the results of this study, there were statistically significant differences in relationships between genders, age, and year of work experiences in relation to total injuries, chemical hazards subscale. Similarly, the study of Yilmaz et al. $(2015)^{[9]}$ found that younger workers are the least experienced group and less occupational safety measures than older age groups, the author also mentioned that this work is very hard for females and they are more liable to hazards than male. In view of that, it is crucial that safety work policies and procedures should be committed by workers, as well, worker education and training and effective supervision to the workplace environment concerning health and safety issues. $^{[19]}$

\section{Conclusion}

This study provides a ground picture of awareness level of occupational health hazards and the use of safety measures 
among the printing workers. Based on the results of this study, current results concluded that the workers exposed to moderate level of occupational hazards, the most hazards among the printing workers were healthy, chemical, injury and psychological hazards As well, the majority of workers stated that there are moderate level of safety measures to occupational hazards in the workplace with negative statistically significant correlation related to total occupational health hazards. This, in turn implies that education of the workers and the reform and making more safe workplaces could be important to reduce the burden of occupational health hazards.

\section{Recommendations}

Based on the results of the current study, it is recommended that, continuous training of the printing workers on safety guidelines and enforcement of standard safety practices to decrease the potential occupational hazards. Design interventions for the targeted groups, thus promoting and upholding better health and environment with safety standards with special attention towards young workers and lower education. Further researches on a larger scale are required to assess the occupational health hazards and safety measures among printing.

\section{Conflicts OF InTEREST Disclosure}

The authors declare that there is no conflict of interest.

\section{REFERENCES}

[1] Marahatta SB, Gautam S, Paudel G, et al. Awareness of Occupational Hazards and Associated Factors among Automobile Repair Artisans in Kathmandu Metropolitan City, Nepal. Indian J Occup Environ Med. 2018 Jan-Apr; 22(1): 49-53. PMid:29743786 https://doi.org/10.4103/ijoem.IJOEM_106_17

[2] Gebremeskel TG, Yimer T. Prevalence of occupational injury and associated factors among building construction workers in Dessie town, Northeast Ethiopia; 2018. Gebremeskel and Yimer BMC Res Notes. 2019; 12: 481. PMid:31382990 https://doi.org/10.118 6/s13104-019-4436-4

[3] Joshua IA, Abubakar I, Gobir AA, et al. Knowledge of occupational hazards and use of preventive measures among bakery workers in Kaduna North Local Government Area, Kaduna State, Nigeria. Arch Med Surg. 2017; 2: 78-83. https://doi.org/10.4103/archms . archms_39_17

[4] Kiurski JS, Maric BB, Aksentijevic SM, et al. Occupational hazards in printing industry. Int. J. Environ. Sci. Technol. 2016; 13: 955-972. https://doi.org/10.1007/s13762-016-0937-z

[5] Prica M, Kecić V, Adamović S, et al. Occupational Exposure to Hazardous Substances in Printing Industry Paper 14 Proceedings of 8th International Engineering Symposium at Bánki . 2016; 1-8.

[6] Gutzky R. Risks in printing companies. 2017. Available from: https://bizfluent.com/list-6804380-risks-pri nting-companies.html

[7] Othman N, Lerk NL, Chelliapan S, et al. Risk Assessment and Control Measures for the Printing Ink Production Process, International Journal of Civil Engineering and Technology. 2017; 8(10): 41-55.

[8] Topcu S, Ardahan M. Occupational Health Nursing and Pioneer Leaders from Past to Present. International Journal of Caring Sciences. 2019; 12(3): 1931.

[9] Yilmaz F, Sevindik O, Akpolat C. Safety in Turkish Printing and Publishing Sector; Evaluation of Awareness Levels of the Workers on Health and Safety Issues. Int. J. of Multidisciplinary and Current Research. Jan/Feb 2015.
[10] Tsai CJ, Mao IF, Ting JY, et al. Quality of Chemical Safety Information in Printing Industry. Ann. Occup. Hyg. 2016; 60(3): 361-370. PMid:26568584 https://doi.org/10.1093/annhyg/mev079

[11] Denton M, Zeytinoglu IU, Brookman C, et al. Personal support workers' perception of safety in a changing world of work. Safety in Health. 2013; 4: 2. https://doi .org/10.1186/s40886-018-0 069- $\mathrm{x}$

[12] Kelloway EK, Francis K, Gatien B. Management of Occupational Health and Safety, 7th edition. Toronto: Nelson. 2017.

[13] Martin, A. What Are the Dangers of Sitting Next to a Copy Machine; 2019. https://www.techwalla.com/articles/what-are-the-dangers-ofsitting-next-to-a-copy-machine

[14] Kitamura H, Terunuma N, Kurosaki S, et al. A Cohort Study on Self-Reported Respiratory Symptoms of Toner-Handling Workers: Cross-Sectional and Longitudinal Analysis from 2003 to 2008. BioMed Research International. 2014; 1-10. PMid:24719889 https : //doi.org/10.1155/2014/826757

[15] Starovoytova D. Hazards and Risks at Rotary Screen Printing (Part 3/6): Psychosocial and Mechanical exposure. Industrial Engineering Letters. 2017; 7(6): 26-48.

[16] Goebel A. Recommendations for the safe handling of laser printers. Institute for Occupational Safety and Health of the German Social Accident Insurance (IFA); 2015. Available from: https://www.dguv.de/medien/ifa/en/pra/laserdru cker/recommendations_laser_printers.pdf

[17] Casey M, Hawley B. Evaluation of Legionnaires' disease risk and other health hazards at an offset printing company. Health Hazard Evaluation Report 2015-0065-3252; 2016. 1-28.

[18] Ibrahim AA, Elgewely MS, Sally A, et al. Environmental Safety Assessment of a Printing Plant in Cairo, Egypt. Medical Integrated Students. Research Journal (MISRJ). September 2018; 1(1): 30-38. https://doi.org/10.21608/misrj.2018.12824

[19] Asumeng M, Asamani L, Afful1 J, et al. Occupational safety and health issues in Ghana: Strategies for improving employee and health at workplace. International Journal of Business and Management Review. 2015; 3(9): 60-79. 